\title{
Neki pokazatelji poslovanja veterinarskih organizacija u svjetlu općih gospodarskih
} trendova u Hrvatskoj

\author{
Denis Cvitković, Marko Tadić, Selim Pašić i Marina Pavlak
}

\section{Sažetak}

Od početka svjetske gospodarske recesije 2008. godine pa i uoči nje, praćene su promjene gospodarskih pokazatelja u veterinarskim stanicama i ambulantama. Neki autori su u nekoliko navrata pisali o potencijalnim uzrocima i posljedicama krize na poslovanje veterinarskih organizacija. U žarištu interesa bilo je više pokazatelja od kojih su tri praćena $\mathrm{u}$ ovom istraživanju. To su: prosječna neto plaća, broj zaposlenih i ukupni prihod. Oni su prikazani za razdoblje od 2003. do 2017. godine. Radi stjecanja jasnijeg uvida u okolnosti u kojima su poslovale, našu smo pažnju proširili i na općenitije pokazatelje gospodarske aktivnosti na razini ukupnog gospodarstva (bruto domaći proizvod, javni dug, zaposlenost, broj i dobna struktura stanovništva, uvoz i izvoz) i poljoprivrede kao bitne odrednice aktivnosti veterinarskih organizacija. Naime, rezultati istraživanja pojedinih autora pokazuju da je recesija više naštetila veterinarstvu negoli ukupnom gospodarstvu pa smo željeli u široj ekonomskoj slici uočiti naznake buduće gospodarske stvarnosti i upozoriti na njih. S obzirom na to da su gospodarski trendovi potaknuti i vođeni potrebama ljudi, demografski po- datci mogu pomoći pri otkrivanju makro i mikro trendova. Zato smo u promatranje uključili i demografske pokazatelje. Ukupni prihod i broj zaposlenih u veterinarskim stanicama smanjivali su se, dok su plaće lagano rasle do 2008. a zatim stagnirale. U veterinarskim ambulantama, za razliku od stanica, svi pokazatelji su rasli, no u godinama nakon početka recesije plaće su uglavnom stagnirale ili lagano padale. U 2017. godini zabilježen je lagani porast neto plaća i u veterinarskim stanicama i u veterinarskim ambulantama. Zabilježene promjene u kretanju poljoprivrednih i općih demografskih i gospodarskih trendova poput: bitnog smanjenja broja reproduktivnih životinja i proizvodnje mlijeka i jaja, starenja ljudske populacije i smanjenja nataliteta, stalno rastućeg uvoza hrane i pića i uvoza općenito te uočena jaka korelacija između duga i broja stanovnika, i rastući pritisak na novo zaduživanje upućuju na izvjesnu daljnju stagnaciju ili smanjivanje gospodarskih aktivnosti veterinarskih organizacija. Porast proizvodnje bio je najizraženiji u broju košnica i proizvonji meda, u uzgoju ovaca i konja te tovu pilića. Evidentno je da su se najviše smanjivale one sto-

Dr. sc. Denis CVITKOVIĆ*, dr. med. vet., docent, (dopisni autor, e-mail: denis.cvitkovic@vef.hr), dr. sc. Selim PAŠIĆ, dipl. ing., docent, dr. sc. Marina PAVLAK, dr. med. vet., redoviti profesor, Veterinarski fakultet Sveučilišta u Zagrebu, Hrvatska; dr. sc. Marko TADIĆ dr. med. vet., redoviti profesor u mirovini, Hrvatska 
čarske proivodnje koje zahtijevaju više vještine, potrošenog vremena i intenzivnijeg rada, dok su porasle one koje traže manje rada i jednostavnije postupke. Struktura proizvodnje prilagođavala se potrebama i mogućnostima koje proizlaze iz strurkture radne snage.

Ključne riječi: veterinarske organizacije, poslovanje, stočarska proizvodnja, demografski pokazatelji, dug

\section{Uvod}

Od početka svjetske gospodarske recesije 2008. godine pa i uoči nje, praćene su promjene gospodarskih pokazatelja u veterinarskim stanicama i ambulantama. Tadić i sur. (2006., 2009., 2012., 2013. i 2016.) u nekoliko su navrata pisali o potencijalnim uzrocima i posljedicama krize na poslovanje veterinarskih organizacija. U žarištu interesa bilo je nekoliko pokazatelja od kojih su tri praćena u ovom istraživanju. To su: prosječna neto plaća, broj zaposlenih i ukupni prihod. Oni su prikazani za razdoblje od 2003. do 2017. godine. Radi stjecanja jasnijeg uvida $u$ okolnosti u kojima su poslovale, u ovom radu našu pažnju proširili smo i na općenitije pokazatelje gospodarske aktivnosti na razini ukupnog gospodarstva (bruto domaći proizvod, javni dug, zaposlenost, broj i dobna struktura stanovništva, uvoz i izvoz) i poljoprivrede kao bitne odrednice aktivnosti veterinarskih organizacija. Naime, rezultati istraživanja (Tadić i sur., 2013.) pokazuju da je recesija više naštetila veterinarstvu negoli ukupnom gospodarstvu pa smo željeli u široj ekonomskoj slici uočiti naznake buduće gospodarske stvarnosti i upozoriti na njih. S obzirom na to da su trendovi u gospodarskoj aktivnosti zapravo potaknuti i vođeni potrebama i navikama ljudi, Dent (2015.) tvrdi da demografski podatci mogu pomoći pri otkrivanju makro i mikro trendova. Zato smo u promatranje uključili i demografske pokazatelje poput već spomenutog broja i dobne strukture stanovništva i broja zaposlenih, zatim broj umirovljenika, broj obiteljske radne sna- ge na poljoprivrednim gospodarstvima i njihovu dobnu strukturu. Od pokazatelja iz područja poljoprivredne proizvodnje usredotočili smo se na one najdramatičnije, a koji istovremeno bitno utječu na zaposlenost pa time i uvoz odnosno izvoz (broj rasplodnih goveda, broj rasplodnih svinja, broj rasplodnih ovaca, broj kokoši i tovnih pilića, proizvodnja jaja, broj košnica i proizvodnja meda, količina otkupljenog kravljeg mlijeka te ukupna količina mlijeka proizvedenog na obiteljskim poljoprivrednim gospodarstvima).

\section{Materijali i metode}

Podatci prikupljeni za 47 veterinarskih stanica $(79,7 \%$ njihovog ukupnog broja) i 42 veterinarske ambulante $(30,9$ $\%$ njihovog ukupnog broja) odnose se na razdoblje od 2003. do 2017. godine, a preuzeli smo ih s Hrvatskog poslovnog portala Poslovna.Hr (izdavač Bisnode d.o.o.). Prikupljeni se podatci odnose na neto plaće $\mathrm{u}$ veterinarskim stanicama i ambulantama, broj zaposlenih i ukupni prihod. Podatci o bruto domaćem proizvodu i javnom dugu preuzeti su sa stranica Međunarodnog monetarnog fonda, podatci o broju umirovljenika i prosječnim mirovinama $s$ mrežnih stranica Hrvatskog zavoda za mirovinsko osiguranje, a svi ostali podatci s mrežnih stranica Državnog zavoda za statistiku.

Podatke smo obradili pripadnim statističkim metodama uporabom programa STATISTICA 12 i Excel. 


\section{Rezultati}

Grafikon 1. prikazuje promjene broja zaposlenih $\mathrm{u}$ veterinarskim stanicama i ambulantama od 2003. do 2017. godine.

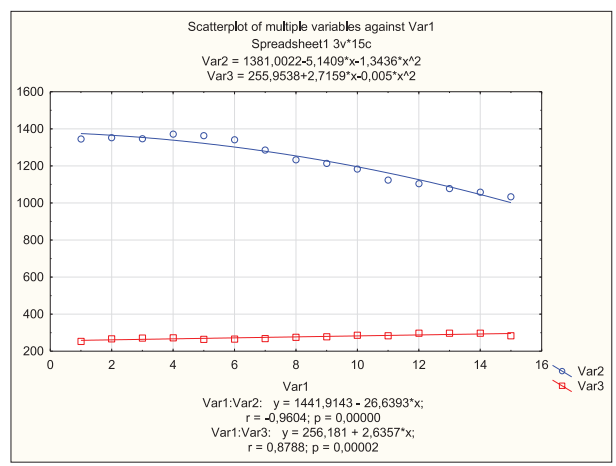

Grafikon 1. Promjene broja zaposlenih u veterinarskim stanicama (Var2) i veterinarskim ambulantama (Var3) od 2003. do 2017.

Podatci o broju zaposlenih $u$ veterinarskim stanicama odnose se na 47 veterinarskih stanica što je 79,7 \% $\left(\mathrm{s}_{\mathrm{p}}=0,052\right)$ njihova ukupnog broja u Hrvatskoj prema evidenciji Hrvatske veterinarske komore. Prosječni broj zaposlenih po veterinarskoj stanici smanjivao se $\mathrm{u}$ označenom razdoblju 1,87 \% prosječno godišnje. Najmanje zaposlenih po veterinarskoj stanici bilo je 2, a najviše 87 . Valja naznačiti da veterinarske stanice po tome obilježju nisu bile osobito homogen skup (V=59,93-64,25\%), ali je ipak njihova razdioba bila samo umjereno asimetrična i spljoštenija od normalne. Ako bi prosječni broj zaposlenih u veterinarskim stanicama u našem uzorku tijekom 2017. godine projicirali na ukupni broj veterinarskih stanica u Hrvatskoj prema evidenciji Hrvatske veterinarske komore, onda bi ukupno broj zaposlenih mogao biti 1,297 zaposlenih.

Razvidno je da je gotovo četvrtina svih veterinarskih stanica u skupini mikro-poduzeća, da ih je gotovo tri četvrtine u skupini malih poduzeća, a da ih je samo $2 \%$ u skupini srednje velikih poduzeća. To ne iznenađuje jer i u strukturi poduzeća u Hrvatskoj po svojoj brojnosti i po ukupnom broju zaposlenih dominiraju mikro i mala poduzeća.

Podatke o poslovanju prikupili smo i od 42 veterinarske ambulante što je manje od trećine $\left(30,9 \% ; s_{p}=0,0396\right)$ njihovog ukupnog broja prema popisu veterinarskih ambulanata što ih vodi Hrvatska veterinarska komora. Tijekom označenog razdoblje broj zaposlenih $\mathrm{u}$ veterinarskim ambulantama bio je između 1 i 40, a po godinama od 6,02 do 7,10 po prosječnoj ambulanti. Tijekom tog razdoblja prosječni broj zaposlenih po ambulanti povećavao se $0,83 \%$ prosječno godišnje.

Prosječni broj zaposlenih $u$ veterinarskim stanicama bio je značajno $(P<0,01)$ veći nego u veterinarskim ambulantama. Odnos broja zaposlenih u veterinarskim stanicama $i$ veterinarskim ambulantama bio je $4: 1$.

Svakako valja istaknuti da su veterinarske ambulante po tom obilježju manje homogen skup nego veterinarske stanice te da je njihova distribucija asimetrična i znatno šiljatija od normalne razdiobe.

Kretanje ukupnog prihoda veterinarskih stanica i veterinarskih ambulanata prikazano je u Grafikonu 2.

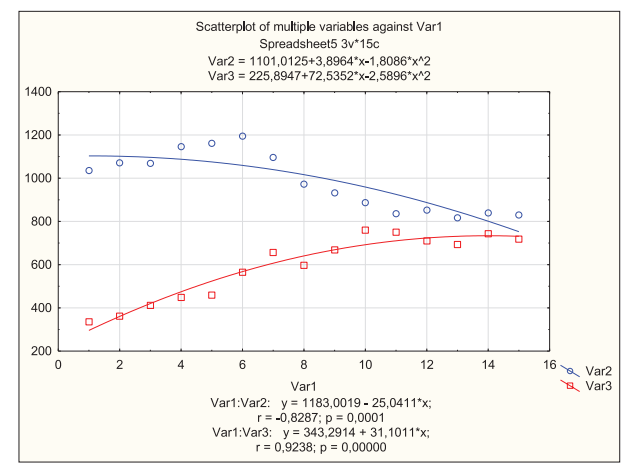

Grafikon 2. Promjene ostvarenog ukupnog prihoda veterinarskih stanica (Var2) i veterinarskih ambulanata (Var3) između 2003. i 2017. godine (Var1) 
Ukupni prihod veterinarskih stanica u promatranom razdoblju pao je za 19,86\%, a veterinarskih ambulanata porastao za 114,38 \%. Promjene prosječne neto plaće $\mathrm{u}$ veterinarskim stanicama, pravnim subjektima i veterinarskim ambulantama prikazane su grafikonima 3. i 4.

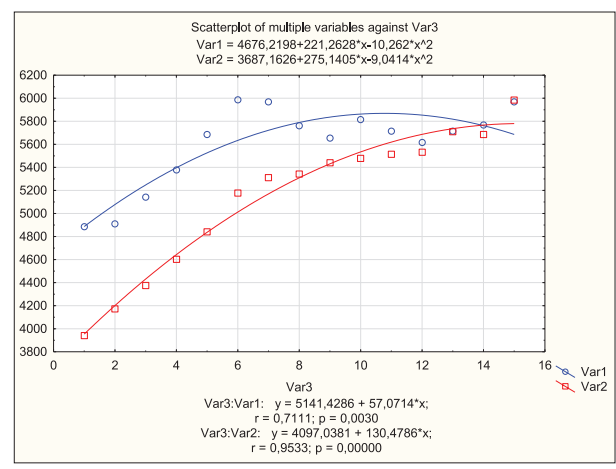

Grafikon 3. Promjene prosječne mjesečne neto isplaćene plaće (HRK) u veterinarskim stanicama (Var1) i u pravnim subjektima (Var2) u Hrvatskoj od 2003. do 2017. (Var3).

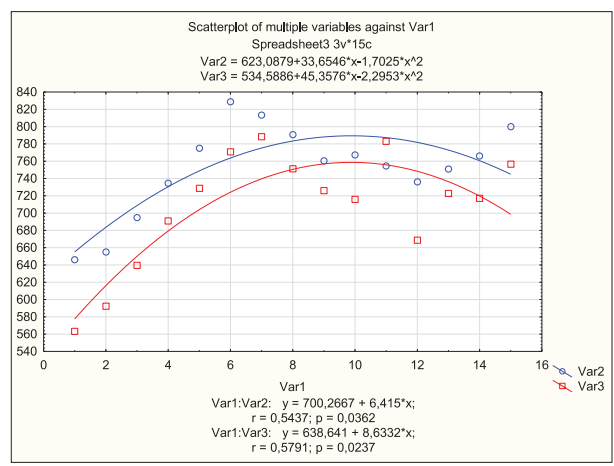

Grafikon 4. Promjene prosječne mjesečne neto plaće (eura) u veterinarskim stanicama (Var2) i u veterinarskim ambulantama (Var3) od 2003. do 2017. (Var1)

Prosječna mjesečna neto plaća u veterinarskim stanicama povećavala se tijekom označenog razdoblja 1,54 \% prosječno godišnje. Postupno se povećavala od 2003. do 2008. godine kada počinje gospodarska recesija u Hrvatskoj.
Slijedi šest recesijski godina postupnog smanjivanja prosječnih mjesečnih neto isplaćenih plaća. Posljednje tri godine promatranog razdoblja plaće su se povećavale $2,82 \%$ prosječno godišnje. Ni te godine nisu dosegle razinu plaća iz 2008. godine.

Prema razini prosječnih mjesečnih neto isplaćenih plaća tijekom cijelog promatranog razdoblja skup veterinarskih stanica bio je prilično homogen (V=18,7\%-28,4\%), a njihova razdioba prema tom obilježju, blago asimetrična i u mjereno spljoštena. Tijekom naznačenog razdoblja uočljive su razlike između najniže prosječne mjesečne neto isplaćene plaće i one najviše koja je 2,59 puta veća od najniže.

$\mathrm{U}$ veterinarskim ambulantama neto plaće su u naznačenom razdoblju porasle za ukupno $34,30 \%$. Najviše su bile 2009. godine i do 2017. nisu ponovo dosegle tu razinu. Na početku razdoblja plaće su $u$ veterinarskim stanicama bile veće od onih $\mathrm{u}$ ambulantama za $14,68 \%$ i smanjivale se da bi na kraju razdoblja bile samo 5,76 \% veće, dok su u usporedbi s prosječnim neto plaćama $\mathrm{u}$ pravnim subjektima veterinarske stanice 2003. isplatile $22,69 \%$ veću plaću, a ambulante gotovo $7 \%$ veću. Godine 2017. plaće su u veterinarskim stanicama bile samo $0,50 \%$ veće, a u ambulantama čak 4,98\% manje od prosjeka u pravnim subjektima RH.

$\mathrm{U}$ istom razdoblju broj rasplodnih goveda pao je za 31,10\%, rasplodnih svinja za 36,11 \%, kokoši za 47,65 \% i kokošjih jaja za 25,10 \%. Porastao je broj rasplodnih ovaca za 29,09 \%, broj košnica za 266,13\%, proizvodnja meda za $402,97 \%$ (4 puta), broj konja za 157,88 \% i broj tovljenih pilića za 48,36 \%. Prema dostupnim podatcima, od 2008. do 2018. godine količina otkupljenog kravljeg mlijeka u mljekarama pala je za 31,06 \%, a količina proizvedenog kravljeg, ovčjeg i kozjeg mlijeka na obiteljskim poljoprivrednim gospodarstvima (OPG-ima) do 
2017. godine za $37,79 \%$. Istovremeno je količina mlijeka, koju su OPG-i predali mljekarima, pala za 51,55 \%, a kućna potrošnja mlijeka na OPG-ima pala za $19,19 \%$.

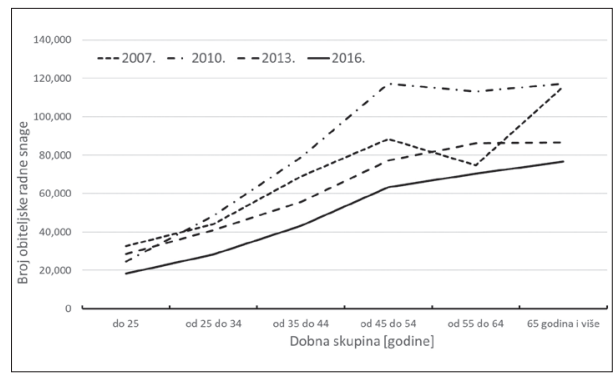

Grafikon 5. Broj obiteljske radne snage na poljoprivrednim gospodarstvima između 2007. i 2016. godine

Brojnost obiteljske radne snage na poljoprivrednim gospodarstvima prikazana je na Grafikonu 5.

Ukupni broj radne snage na gospodarstvima pao je $\mathrm{u}$ tih deset godina za 29,19\%. Međutim, po dobnim skupinama najveći pad je u skupini do 25 godina gdje iznosi $43,78 \%$ a slijedi ga pad u skupini od 35 do 44 godine gdje iznosi 37,09 \%. Vidljivo je da je najbrojnija radna snaga po skupinama ona starija od 65 godina.

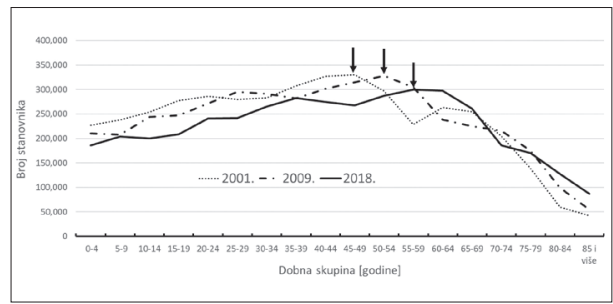

Grafikon 6. Stanovništvo RH po dobnim skupinama 2001., 2009. i 2018. godine

Sličan iako blaži trend može se primijetiti i na razini ukupnog stanovništva. Grafikon 6. prikazuje broj stanovnika u Hrvatskoj po dobnim skupinama između 2001. i 2018. godine.

Jasno je izražen trend starenja i smanjenja brojnosti. Najbrojnija dobna skupina 2001. godine bila je ona od 45-49 godina, a 2018. ona od 55-59 godina starosti. Istovremeno se udio starijih od 85 godina povećao za nešto više od 2 puta. Ukupan broj stanovnika manji je za 4,93 $\%$. Grafikon 7. preuzet je iz statističkog ljetopisa Državnog zavoda za statistiku, a prikazuje prirodno kretanje stanovništva od 1982. do 2017. godine i prati broj živorođenih i umrlih u RH. Godine 2017. broj umrlih bio je gotovo $45 \%$ veći od broja rođenih.

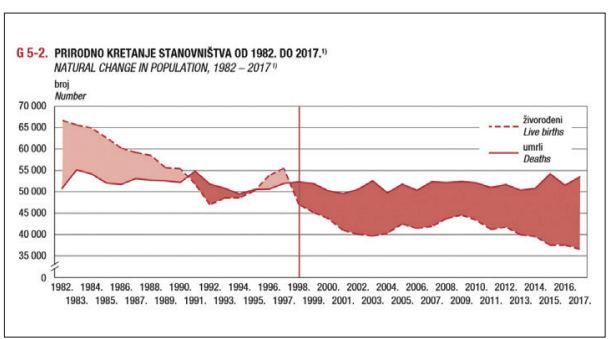

Grafikon 7. Prirodno kretanje stanovništva u RH od 1982. do 2017. godine (Anonymous, 2020.)

Broj umirovljenika povećao se od 2001. do 2019. godine za 20,25 \% dok se broj zaposlenih $\mathrm{u}$ istom razdoblju povećao tek za 12,76\%. Prosječna mirovina iznosila je 2017. godine 340 $€$, a prosječna neto plaća u pravnim subjektima $796 €$. Omjer broja zaposlenih prema broju umirovljenika bio je najpovoljniji 2008. godine kada je iznosio 1,36 zaposlenih prema jednom umirovljeniku, a 2018. iznosio je 1,16 .

Grafikon 8. prikazuje odnos između duga (duga opće države) izraženog kao postotak bruto domaćeg proizvoda (BDP-a) i broja stanovnika. Koeficijent korelacije $(R)$ izrazito je visok i iznosi 0,98 što upućuje na vrlo jaku negativnu povezanost ove dvije varijable. 


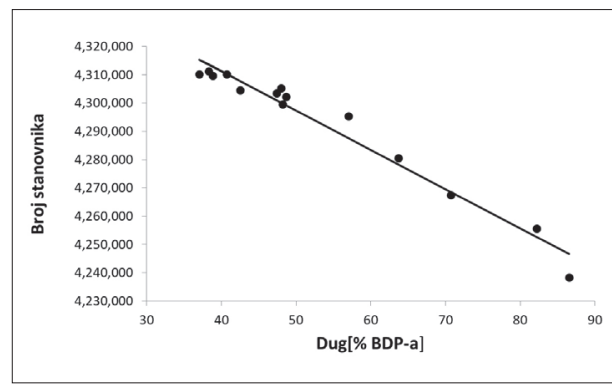

Grafikon 8. Korelacija između duga i broja stanovnika u Hrvatskoj od 2001. do 2014. godine

Uvoz hrane i pića povećao se između 2004. i 2017. godine za 130,64\%, a pokrivenost uvoza izvozom bila je 2018 . godine $55,12 \%$. Ukupni uvoz porastao je od 2000. do 2017. godine za 74,60 \%, a pokrivenost uvoza izvozom iznosila je 2017. godine $64,03 \%$.

\section{Rasprava}

Predstavljeni rezultati istraživanja upućuju na nekoliko bitnih trendova. Kod veterinarskih stanica uočen je trend smanjivanja ukupnog prihoda $\mathrm{u}$ cijelom promatranom razdoblju, a kod veterinarskih ambulanata $u$ početku znatan porast ukupnih prihoda sve do 2012. godine, a zatim stagnacija i umjeren pad. Istovremeno broj zaposlenih kao i iznos prosječno isplaćenih neto plaća pratili su isti obrazac. U veterinarskim stanicama prosječan broj zaposlenih se smanjivao, a u veterinarskim ambulantama povećavao, no zadržao se u prosjeku oko omjera $4: 1$, tj. prosječna veterinarska stanica imala je oko 4 puta više zaposlenih od prosječne veterinarske ambulante. Razlika $\mathrm{u}$ visini prosječne neto plaća $\mathrm{u}$ veterinarskim stanicama $\mathrm{u}$ odnosu na veterinarske ambulante iznosila je 14,68 \% na početku promatranog razdoblja (2003.), dok je na kraju razdoblja iznosila samo $5,76 \%$, a to potvrđuje obrazac uočen $u$ kretanju ukupnih prihoda. U odnosu na neto plaće isplaćene $\mathrm{u}$ pravnim subjektima uočljivo je smanjivanje plaća $u$ promatranim veterinarskim stanicama kroz cijelo razdoblje, a kod veterinarskih ambulanata porast plaća do 2009. godine i tada smanjivanje sve do 2017. godine kada je prosječna neto plaća u veterinarskim ambulantama bila gotovo $5 \%$ niža od prosječne neto plaće $u$ pravnim subjektima.

Pokazatelji poljoprivredne aktivnosti ukazivali su u promatranom razdoblju na pad proizvodnih i demografskih kapaciteta. Broj rasplodnih goveda, svinja i kokoši je pao što ukazuje na smanjenje proizvodnje i zaposlenosti koje se između ostalog zrcale $u$ smanjenom otkupu i proizvodnji mlijeka i jaja te smanjenju broja obiteljske radne snage na poljoprivrednim gospodarstvima. Dobna struktura te radne snage izrazito je nepovoljna jer su od svih dobnih skupina najzastupljenije osobe starije od 65 godina, s trendom rasta. Istovremeno, udio mlade radne snage drastično je smanjen i u 10 promatranih godina (od 2007. do 2016. god.) pao je za gotovo $44 \%$. Neiskorišteni proizvodni kapaciteti u stočarstvu predstavljaju istovremeno i propuštene prilike za zapošljavanje. Porast proizvodnje bio je najizraženiji u držanju pčela i proizvodnji meda, u uzgoju ovaca i konja te tovu pilića. Evidentno je da su se najviše smanjile one stočarske proizvodnje koje zahtijevaju više vještine, potrošenog vremena i težeg rada, dok su porasle one koje traže manje rada i jednostavnije postupke. Istovremeno, prema informacijama $s$ terena od strane vlasnika veterinarskih organizacija, one organizacije koje su svoje poslovanje proširile i na zadovoljavanje potreba pčelara bilježe rast prometa u segmentu pčelarstva. Moglo bi se zaključiti da je struktura proizvodnje "proizvod" (posljedica, učinak) strukture radne snage, što je sukladno s ranije izrečenim stavom da su trendovi u gospodarskoj 
aktivnosti potaknuti i vođeni potrebama i navikama ljudi.

$\mathrm{Na}$ razini ukupnog broja stanovnika i njihove dobne strukture uočeno je vrlo slično kretanje. Stanovništvo $\mathrm{u}$ prosjeku postaje sve starije i rađa se sve manje djece, a broj umirovljenika se povećava po većoj stopi od broja zaposlenih. Godine 2018. taj je omjer iznosio 1,16 zaposlenih na jednog umirovljenika što predstavlja veliko opterećenje za mirovinski sustav i generira povećanu potrebu za zaduživanjem države. To istovremeno znači polagano, ali vrlo izvjesno siromašenje stanovništva i povećanje sklonosti ka novom zaduživanju, što će se neminovno odraziti na potrošnju o kojoj ovise sve djelatnosti pa tako i veterinarske. Dodajući tome trend smanjenja proizvodnih kapaciteta u stočarskoj proizvodnji (s iznimkom ovčarske, peradarske i pčelarske proizvodnje te broja konja), već spomenutog bitnog smanjenja broja mlade radne snage na poljoprivrednim gospodarstvima te stalno rastućeg uvoza hrane i pića kao i uvoza općenito, za očekivati je daljnju stagnaciju ili pad gospodarskih aktivnosti veterinarskih organizacija.

Naime, već su ranije Tadić i sur. (2016.) primijetili proces prestajanja postojanja veterinarskih organizacija. Osobito je zanimljiva i znakovita uočena povezanost između veličine duga države izraženog kao postotak BDP-a i broja stanovnika. U takvim demografskim okolnostima teško je za očekivati brzu i bitnu promjenu nabolje.

\section{Literatura}

1. Anon (2020): https://www.dzs.hr/Hrv_Eng/ ljetopis/2018/sljh2018.pdf, 03.03.2020.

2. DENT, H. (2015): The demographic cliff: how to survive and prosper during the great deflation ahead. New York: Portfolio/Penguin.

3. TADIĆ, M. (2012): Posljedice recesije u hrvatskom veterinarstvu. Vet. stn. 43, 69-75.

4. TADIĆ, M. i J. ŠIMIČIĆ (2006): Društveni ugled veterinarske profesije i ekonomski položaj veterinarstva u Republici Hrvatskoj. Vet. stn. 37, 15-23.

5. TADIĆ, M., V, ANIĆ i A. GAŠPAR (2016): Kraj recesije u hrvatskom veterinarstvu. Vet. stn. 47, 415422.

6. TADIĆ, M., V. ANIĆ i M. PAVLAK (2013): Razdoblje recesije u hrvatskom veterinarstvu. Vet. stn. 44, 1-9.

7. TADIĆ, M., V. TADIĆ, D. CVITKOVIĆ, M. PAVLAK i V. ANIĆ (2009): Recesija i veterinarstvo. Vet. stn. $40,337-351$

\section{Business indicators of veterinary organizations in the light of general economic trends in Croatia}

Denis CVITKOVIĆ, DVM, MBA, PhD, Assistant Professor, Selim PAŠIĆ, BSc, PhD, Assistant Professor, Marina PAVLAK, DVM, PhD, Full Professor, Faculty of Veterinary Medicine University of Zagreb, Croatia; Marko TADIĆ, DVM, PhD, Full Professor in Retirement, Croatia

Changes in economic indicators in veterinary organizations have long been monitored, particularly since the beginning of the global economic recession in 2008 . There are a number of reports on the potential causes and consequences of the 2008 crisis on the operations of veterinary organizations, focusing on a number of indicators, three of which are considered here: average net salary, number of employees and total income. These data were collected for the period 2003-2017. To obtain clearer insight into the circumstances of operations, we extended our attention to more general indicators of economic activity at the level of the national economy (gross domestic product, public debt, employment, population and age structure, imports and exports) and agriculture as an important component of veterinary activities. Other studies have shown that the recession did more harm to veterinary medicine than to the general economy, and therefore, we wanted to examine this and warn about the future economic reality in the overall economic picture. Given that economic trends are 
driven by human needs, demographics can help identify macro and micro trends and therefore demographic indicators were included in the study. Total income and number of employees at larger veterinary organizations declined as wages rose slightly until 2008 and then stagnated. In smaller veterinary practices, all indicators rose, but in the years following the onset of the recession, wages generally stagnated or fell slightly. In 2017, there was a slight increase in net salaries in both types of veterinary organizations. Changes in agricultural and general demographic trends, such as a significant decrease in the number of reproductive animals and milk production, an aging human population and a decrease in the birth rate, together with the strong correlation between debt and population, suggest certain further stagnation or decrease in the economic activity of veterinary organizations.

Key words: veterinary organizations; business; livestock production; demographic indicators; debt 